\title{
ON THE POLITICAL IMPACT OF THE INGOUR BATTLE OF NOVEMBER 6, 1855
}

\author{
Dmitriy Yu. Plotnikov \\ Institute of History of the Siberian Branch, RAS, \\ Novosibirsk, Russian Federation
}

\begin{abstract}
Introduction. The article analyzes the battle on the Ingour river on November 6, 1855 from the political perspective in order to establish its role in the Caucasian campaign of 1855 of the Crimean war (18531856). Methods. Using the approach created by Carl von Clausewitz and developed by Alexander Svechin, the author views war as the continuation of politics and explores the political impact of the Ingour battle regarding its connection with the development of guerilla war in Mingrelia against the Turkish army under Omer-pasha (Ömer Lütfi Paşa). Analysis. Tactical analysis of the battle demonstrates that its organization and conduct on Russian side included considerable flaws. However, political analysis allows understanding that the impact of the Ingour battle went beyond its immediate tactical outcome. Political instability in Mingrelia demanded imperatively that major-general I.K. Bagration-Mukhranskiy, who commanded Russian Gurian force, would confront Omer-pasha at Mingrelian border in order to confirm the political credibility of Russian authorities among the local population. Discussion. Russian readiness to fight for Mingrelia influenced the political situation positively and contributed to the development of guerilla war against Omer-pasha. It was especially beneficial in the difficult conditions of Batum operational area and made a significant contribution to the outcome of the campaign. Thus, it is established in the article that one should view the Ingour battle not as a woeful defeat, but as the sensible tactical sacrifice for political ends that yielded considerable results and influenced the outcome of the 1855 Caucasian campaign in an important way.

Key words: Crimean War, Caucasian theater of operations, Mingrelia, Ingour, I.K. Bagration-Mukhranskiy, Omer-pasha.

Citation. Plotnikov D.Yu. On the Political Impact of the Ingour Battle of November 6, 1855. Vestnik Volgogradskogo gosudarstvennogo universiteta. Seriya 4, Istoriya. Regionovedenie. Mezhdunarodnye otnosheniya [Science Journal of Volgograd State University. History. Area Studies. International Relations], 2019, vol. 24, no. 1, pp. 174-182. (in Russian). DOI: https://doi.org/10.15688/jvolsu4.2019.1.15
\end{abstract}

УДК 94(47).073.5

ББК $63.3(2) 52$
Дата поступления статьи: 13.08.2018 Дата принятия статьи: 01.12.2018

\section{О ПОЛИТИЧЕСКОМ ЗНАЧЕНИИ ИНГУРСКОГО СРАЖЕНИЯ 25 ОКТЯБРЯ (6 НОЯБРЯ) 1855 ГОДА}

\author{
Дмитрий Юрьевич Плотников \\ Институт истории Сибирского отделения РАН, г. Новосибирск, Российская Федерация
}

Аннотация. В статье проанализировано с политической точки зрения сражение на р. Ингур 25 октября (6 ноября) 1855 года. Цель анализа - установить значение Ингурского сражения в рамках кампании 1855 г. на Кавказском ТВД Крымской войны 1853-1856 годов. Используя подход, предложенный К. Клаузевицем и развитый А.А. Свечиным, автор рассматривает войну как продолжение политики и исследует связь Ингурс。 кого боя с развитием партизанской войны против турецкой армии Омер-паши в Мингрелии. Тактический разбор сражения демонстрирует, что его организация и ведение с русской стороны содержали серьезные ошибки. Однако рассмотрение событий с политической точки зрения позволяет понять, что значение Ингурского сражения выходило за рамки его непосредственного тактического результата. В условиях политической нестабильности в регионе генерал-майор И.К. Багратион-Мухранский, командовавший русским Гурий- 
ским отрядом, должен был дать Омер-паше отпор на границе Мингрелии, чтобы подтвердить в глазах местного населения состоятельность русской власти. Готовность России сражаться за Мингрелию благоприятно повлияла на обстановку и способствовала развитию партизанской войны против армии Омер-паши. Это было особенно выгодно в сложных условиях батумского оперативного направления и внесло значительный вклад в исход кампании. Таким образом, установлено, что Ингурское сражение следует рассматривать не как плачевное поражение, а как разумное принесение тактики в жертву политике, положительные плоды которого значительно повлияли на исход Кавказской кампании 1855 года.

Ключевые слова: Крымская война, Кавказский ТВД, Мингрелия, Ингур, И.К. Багратион-Мухранский, Омер-паша.

Цитирование. Плотников Д. Ю. О политическом значении Ингурского сражения 25 октября (6 ноября) 1855 года // Вестник Волгоградского государственного университета. Серия 4, История. Регионоведение. Международные отношения. - 2019. - Т. 24, № 1. - C. 174-182. - DOI: https://doi.org/10.15688/jvolsu4.2019.1.15

Введение. Крымская война 1853 1856 гг. стала первым со времени Наполеоновских войн вооруженным конфликтом великих европейских держав и важной вехой в развитии военного искусства. Новые технологии постепенно вели к появлению соответствующих тактических и оперативных форм, а принципиально иной характер противостояния (борьба за ограниченные цели вместо стремления к полному сокрушению противника, столь характерного для Наполеоновских войн) предоставлял богатый материал для обогащения стратегического мышления. При всем этом было бы принципиально неверно изучать лишь военную сторону событий 1853-1856 гг: по классическому определению К. Клаузевица, Крымская война, как и всякая другая, являлась не вещью в себе, а продолжением политики иными средствами [11, с. 15]. Следовательно, для того чтобы понять причины, ход и результаты Крымской войны во всей их полноте, каждый эпизод противостояния следует рассматривать не только со строго военной точки зрения, но и в политическом контексте. Сражение на р. Ингур 25 октября (6 ноября) 1855 г. на Кавказском театре военных действий (далее - ТВД) войны наглядно иллюстрирует этот тезис. Только взгляд с политической точки зрения позволяет понять влияние Ингурского сражения на настроения местного населения и развитие в Мингрелии партизанской войны, а значит, и значение сражения в контексте Кавказской кампании 1855 г. в целом.

Историография и методы. Будучи одним из крупнейших полевых сражений Крымской войны на Кавказе, Ингурский бой неоднократно удостаивался внимания в историографии, но исследователи не всегда опи- сывали его сколько-нибудь подробно. К примеру, Л.Г. Бескровный вообще не отметил бой на р. Ингур, ограничившись констатацией русского отступления из Мингрелии под давлением турецких войск Омер-паши [3, с. 281]. Так же немногословно на факт поражения численно уступающих русских войск указали Е.В. Тарле [14, с. 492], Х.-М. Ибрагимбейли [9, с. 330-331], В.В. Дегоев [8, с. 139] и Дж. Бадем [19, p. 253].

Отечественные историки, рассматривавшие сражение подробнее, нередко преподносили его в максимально благоприятном для России виде, несмотря на факт безоговорочного поражения. М.И. Богданович в детальном описании боя уделил особое внимание храбрости русского Гурийского отряда и голословно заявил, что турецкая сторона существенно занизила свои потери, которые должны были превышать русские [5, с. 625]. Е.Е. Бурчуладзе тоже подчеркнул доблесть русских войск и, объясняя их неудачу, указал на якобы четырехкратное превосходство турок в силах 36000 чел. против 9000 чел. [7, с. 16-17], что является ошибкой, поскольку турецкие силы не превышали 20000 чел. [21, p. 94]. Помимо этого Е.Е. Бурчуладзе, как и М.И. Богданович, без ссылок на источники заявил, что турецкие потери были «в несколько раз больше» русских [7, с. 17]. Н.В. Скрицкий также привел ошибочные цифры, указывающие на четырехкратное превосходство турок, и отметил, что русские войска упорно защищали позицию и лишь «обходной маневр превосходящих сил турок вынудил Гурийский отряд отойти» [17, с. 377]. Дальше всего по этому пути пошел И.В. Бестужев: помимо указания на «подавляющее численное превосходство» $[4$, с. 65$]$ турецких войск 
(все тех же воображаемых 36000 чел.) он объявил Ингур «неудачей» турок [4, с. 54].

Некоторые авторы предпочли прославлению русского оружия обоснованную критику. Наибольшего внимания заслуживает совместная монография У.Э.Д. Аллена и П. Муратова, упрекнувших командование Гурийского отряда за дробление сил и ослабление резерва, в результате чего русские войска оказались растянутыми вдоль течения реки на нескольких изолированных позициях без возможности серьезно усилить какую-либо из них в нужный момент [18, p. 98].

Отношения местного населения с оккупационными войсками историография рассматривает в качестве отдельного сюжета, совершенно не связанного с Ингурским боем. Е.Е. Бурчуладзе и М.И. Богданович упомянули, что замысел русского командования подразумевал организацию партизанской войны, но первый ограничился этим заявлением [7, c. 15], а последний считал, что русская сторона так и не успела «возбудить в Мингрелии народную войну» [5, с. 626]. Также Е.Е. Бурчуладзе подчеркнул, что решение «не отдавать Мингрелию без боя» было принципиальным [7, с. 16], а М.И. Богданович отметил, что отказ от боя мог отрицательно повлиять на настроения населения [5, с. 621]. Однако даже два вышеупомянутых автора, рассматривавшие военные действия на западе Грузии в 1855 г. наиболее подробно, не исследовали связь между Ингурским сражением и последовавшей партизанской войной. Другие же историки чаще всего ограничивались общими заявлениями, такими как «народ брался за оружие» [8, с. 139] и «народ встретил турок с оружием в руках» [10, с. 178]. Партизанская война мотивируется в исследованиях бесчинствами нерегулярных турецких войск $[19$, p. 254] и тем, что население считало «господство Турции еще более невыносимым и тяжким» [9, с. 329], но никак не связывается с действиями русской армии. Наиболее наглядно эта тенденция проявляется в формулировке И.В. Бестужева: «Между тем в захваченных турками районах Грузии началась против них партизанская война» [4, с. 65]. В отображении историографии партизанская война в Мингрелии начинается именно «между тем» и действия русских войск, включая сражение на
Ингуре, будто бы не имеют к этому никакого отношения.

Таким образом, историографию Ингурского сражения можно разделить на три группы. Многие авторы ограничиваются простым упоминанием сражения и его исхода, другие стремятся смягчить факт поражения указаниями на доблесть русских войск и многочисленность турок или даже прямым искажением фактов, и наконец, некоторые подвергают планирование и ведение боя с русской стороны суровой, но обоснованной критике. При этом партизанская война против армии Омерпаши рассматривается изолированно от сражения на р. Ингур, и попытки выявить между ними причинно-следственную связь не предпринимались.

Цель работы - проанализировать Ингурское сражение не только с тактической, но и с политической точки зрения, установив его роль в развитии партизанской войны в Мингрелии и общее значение в рамках Кавказской кампании 1855 года. Положенный в основу статьи подход восходит к классической работе К. Клаузевица «О войне», определившей войну как «продолжение политических отношений, проведение их другими средствами» [11, с. 15], и к трудам его последователей, прежде всего выдающегося советского и российского военного историка и теоретика А.А. Свечина [15]. Этот подход исходит из того, что стратегия, оперативное искусство и тактика подчинены политике и должны действовать согласно ее требованиям, а не собственным внутренне присущим им закономерностям при возникновении «конфликта интересов». Таким образом, если в предшествовавшей историографии критика или похвалы в адрес русских войск сосредоточивались исключительно на тактической стороне событий, автор настоящей статьи, уделяя внимание организации и ведению боя с русской стороны, рассматривает Ингурский бой прежде всего в политическом контексте. Как будет показано ниже, только такой подход позволяет верно оценить роль сражения на р. Ингур в Кавказской кампании 1855 г. и увидеть в нем не только тактический эпизод, но и важный элемент политической борьбы.

Исследование опирается на комплекс документальных и нарративных источников. 
Первые представлены делопроизводственной документацией и используются преимущественно для установления данных о планах военно-политического руководства воюющих сторон, численности войск и потерях. Вторые представлены мемуарными источниками и частной перепиской и используются для комплексной характеристики военной и политической обстановки в Мингрелии через ее восприятие современниками и участниками событий. В отсутствие официальной документации нарративные источники также частично привлекаются для установления военно-политических замыслов сторон и количественных данных. В целом привлеченная к исследованию источниковая база достаточна для успешного достижения поставленной цели.

Анализ. Экспедиция Омер-паши и Ингурское сражение. Прежде чем перейти непосредственно к анализу Ингурского сражения, необходимо охарактеризовать общий контекст военных действий в Закавказье в 1855 году. Благодаря одержанным в 1854 г. победам при Нигоети, на р. Чолок и Чингильских высотах, а также при Кюрюкдара, Отдельный Кавказский корпус прочно завладел инициативой, а ослабленная турецкая Анатолийская армия перешла к обороне. В результате кампанию 1855 г. русские войска под началом нового наместника Кавказского и командующего Отдельным Кавказским корпусом генерала от инфантерии Н.Н. Муравьева открыли энергичным наступлением, заняв Ардаган, Баязет, Кагызман и установив плотную блокаду Карса, в котором находились главные силы Анатолийской армии. По мере истощения провианта и фуража положение турецкой крепости становилось критическим. Полковник (позднее бригадный генерал) британской армии Фенвик Вильямс, руководивший обороной, настаивал, что лишь «незамедлительная диверсия в Грузии» [22, p. 73] - энергичное наступление с восточного побережья Черного моря в направлении Тифлиса - могла бы спасти гарнизон Карса и заставить Муравьева отступить от крепости. Командующий турецкими войсками в Крыму Омер-паша придерживался схожего мнения и еще в июле предложил усилить турецкий Батумский корпус своими войсками для наступления в Западной Гру- зии [22, p. 50]. Однако до тех пор, пока продолжалась осада Севастополя, французское командование в лице генерала Пелисье ожесточенно возражало против любого ослабления союзных войск в Крыму [21, p. XXV$\mathrm{XXVI,} \mathrm{32].} \mathrm{В} \mathrm{результате} \mathrm{условия} \mathrm{для} \mathrm{экспе-}$ диции Омер-паши сложились только после успешного для союзников штурма Севастополя 27 августа (8 сентября). К 21 сентября (3 октября) Омер-паша прибыл в Сухум-кале и, потратив некоторое время на организацию бывшего Батумского отряда турецкой армии и вновь прибывающих войск, начал наступление в направлении Кутаиса. К 18 (30) октября передовые части турецкой армии достигли р. Ингур, за которой их готовились встретить русские войска под началом генерал-майора И.К. Багратиона-Мухранского.

Русский Гурийский отряд насчитывал 17 3/4 батальона, 11 казачьих и 82 милиционных сотни и 28 орудий, но из-за вспышек малярии в болотистой Колхидской низменности многие подразделения были далеки от штатного состава. По этой причине общая численность отряда не превышала 9000 чел. пехоты и 6000 чел. иррегулярной конницы [5, с. 620]. Изза необходимости оборонять не только Мингрелию, но и Гурию к Ингуру И.К. БагратионМухранский, как указано в его «Подробном описании дела, бывшаго 25 октября 1855 года на р. Ингур, при вторжении Омер-паши в Мингрелию» (далее - «Подробное описание...»), смог сосредоточить лишь 7 1/2 батальонов, 12 орудий и часть милиции [2, с. 107-108], всего 9200 чел. [5, с. 622]. Армия Омер-паши, за вычетом войск, выделенных для обеспечения береговых баз и коммуникаций, имела в своих рядах 36 батальонов пехоты, насчитывавших 19000 чел., 1000 чел. конницы и 37 орудий [21, p. 94]. Турецкие войска, таким образом, не имели четырехкратного численного преимущества, которое им приписывали некоторые авторы [4, с. $65 ; 7$, с. $16-17 ; 17$, с. 377$]$, но все же более чем вдвое превосходили русские силы численно и втрое - по артиллерии.

В этих условиях тактическая цель И.К. Багратиона-Мухранского была вынужденно скромна: он стремился не остановить или разбить более сильного противника, а лишь измотать его боем и нанести 
ему урон. Сухая осень сделала Ингур легко проходимым вброд, поэтому для переправы одновременно подходило множество пунктов. Свести большую часть войск в мощный мобильный резерв, готовый сбросить противника в реку при начале переправы, генерал не считал возможным, поскольку успеть контратаковать противника прежде, чем тот переправит достаточно войск для обороны плацдарма, было в таких условиях затруднительно, на что военачальник и указал в своем «Подробном описании...» [2, c. 108]. Вместо этого И.К. Багратион-Мухранский растянул большую часть сил вдоль берега реки, заняв несколько наиболее удобных переправ и оставив в резерве 2 батальона с 4 орудиями.

Омер-паша приступил к форсированию реки 25 октября (6 ноября), пробуя переправиться сразу на нескольких пунктах. Противники вступили в ожесточенную перестрелку, и к вечеру туркам, использовавшим превосходство в числе и вооружении, удалось создать угрозу обоим флангам русского расположения. Ночью русские войска оставили позицию. Согласно «Подробному описанию...» боя за авторством русского командующего, потери регулярных войск составили 147 убитых, 245 раненных и 42 пропавших без вести, также пришлось бросить 3 орудия [2, с. 109]. С учетом милиции общая оценка русских потерь в более чем 500 чел., высказанная Е.Е. Бурчуладзе [7, с. 17], выглядит вполне правдоподобно. Однако его же заявление, что турецкие потери были «в несколько раз больше» [7, с. 17], - мнение, встречавшееся в историографии и раньше [5, c. 625], - вызывает гораздо меньше доверия: по данным английских офицеров из армии Омер-паши, урон турецких войск состоял из 68 убитых, 238 раненных и 4 пропавших без вести [20, р. 247].

Нетрудно заметить, что с тактической точки зрения и замысел, и ведение сражения с русской стороны заслуживают критики. План русского военачальника, сформулированный в «Подробном описании...», подразумевал исключительно огневое поражение вражеских войск «в тот короткий промежуток времени, когда они должны бороться с быстротою течения» [2, с. 108]. Но русская артиллерия серьезно уступала вражеской числом орудий, а сильной стороной пехоты была вовсе не огневая, а ударная тактика (и кому как не И.К. Багратиону-Мухранскому, два года назад водившему гренадерскую бригаду в штыки в сражении при Баш-Кадыкляре [12, с. 135], об этом знать!). Неудобства огневой тактики для русских войск только усугублялись тем, что в армии Омер-паши было 4 вооруженных штуцерами стрелковых батальона [21, p. 94], в то время как часть русских войск шла в бой еще с кремневыми ружьями наполеоновской эпохи [6, с. 28]. Английский офицер из армии Омер-паши особо отмечал превосходство винтовок Минье над русскими ружьями [20, p. 249]. Неудивительно, что итоговый размен оказывался далеко не в пользу русской армии, что при численном превосходстве противника было весьма невыгодным исходом для Гурийского отряда. Очевидно, что в тактическом отношении Ингурское сражение было с русской стороны далеко не образцовым. Можно, пожалуй, согласиться с У.Э.Д. Алленом и П.П. Муратовым в том, что 25 октября (6 ноября) 1855 г. «может служить классическим примером того, как не следует оборонять водную преграду» [18, p. 97].

Однако реакция командующего Отдельным Кавказским корпусом генерала от инфантерии Н.Н. Муравьева на это откровенно неудачное столкновение представляет немалый интерес. Хотя потенциально от событий в Мингрелии зависело и происходящее под Карсом, наместник Кавказский, отнюдь не отличавшийся благодушием по отношению к подчиненным, вовсе не был разгневан ни поражением, ни потерями. Напротив, он отмечал в своем письме генерал-лейтенанту В.О. Бебутову, заведовавшему гражданской частью на Кавказе, что И.К. Багратион-Мухранский «человек со способностями и не без военных дарований» [2, с. 144] - вероятно, имел основания действовать именно так. Более того, в послании военному министру В.А. Долгорукову Н.Н. Муравьев особо отметил «известное благоразумие» [2, с. 139] своего подчиненного. Возможно, частично спокойная реакция командующего на неудачу объяснялась тем, что Омер-паши он не особенно опасался $[13$, с. 607$]$. Но даже при этом остается воп- 
рос: какое «известное благоразумие» проявилось в заведомо проигрышном и посредственно спланированном и проведенном сражении?

Для ответа на этот вопрос необходимо отдавать себе отчет в политическом контексте борьбы. Война не является изолированным единоборством двух армий: любой ее акт вытекает из конкретной политической обстановки. Стратегия, оперативное искусство и тактика подчинены политике, и на войне «каждое основное решение принимается под давлением ряда политических домогательств» $[15$, c. 91]. От войск регулярно требуются усилия, ненужные или даже вредные со строго военной точки зрения, но необходимые политически, и потому значение сражений следует расценивать не только по их тактическим результатам и оперативным или стратегическим последствиям, но и в свете политических требований момента.

Момент же делал сражение безусловной необходимостью. Разумеется, с военной точки зрения Ингурский бой с противником, обладавшим численным, техническим и тактическим превосходством, мог привести только к поражению, и его было бы лучше избежать, отложив столкновение до складывания более благоприятных условий. Но для того чтобы отказаться от попыток преградить путь наступающему противнику, открыть ему дорогу вглубь обороняемой территории и ограничиться защитой укрепленных пунктов, действиями на сообщениях и партизанской войной, «государство должно обладать большой внутренней спайкой и значительной моральной сопротивляемостью» $[16$, c. 43]. Мингрелия же никак не могла похвастать такой монолитностью. Напротив, политическая обстановка была нестабильна настолько, что в 1854 г. «симптомы неповиновения и непокорности властям» [6, с. 23] в Суджунском округе потребовали карательной экспедиции. Конечно, среди местного населения было немало и тех, кто сочувствовал России, но их готовность выступить против Омер-паши была далеко не безоговорочной: мингрельцев еще надо было убедить взяться за оружие.

В этой обстановке каждое военное решение И.К. Багратиона-Мухранского было в равной степени политическим актом, предназ- наченным заверить местное население в силе России, ее готовности защищать Мингрелию и общей устойчивости русской власти в Грузии. Командующий Гурийским отрядом очень внимательно относился к любым решениям, способным повлиять на настроения населения. Так, он отсоветовал правительнице Мингрелии княгине Е.А. Дадиани перевозить мебель из Зугдиди в Горди, «чтобы действием этим не смущать населения и не дать понять ему, что предвидится какая-нибудь серьезная опасность для нижней Мингрелии» [6, с. 26]. Не встречать противника на границе и без боя допустить вражескую оккупацию Мингрелии означало в таких условиях полностью подорвать народную веру в возможность (и необходимость) успешной борьбы на стороне России, а значит, и «отказаться от всякой попытки склонить мингрельцев... к народной войне и к партизанским действиям против турок» $[6$, c. 30]. Гурийский отряд не мог рассчитывать на победу над армией Омер-паши, и русский генерал вполне это понимал, но его целью было не сокрушить противника, а показать местному населению, что Россия готова за него сражаться. На берегах Ингура русские войска не дрались за тактический успех, а сдавали экзамен на состоятельность и легитимность российской власти в глазах мингрельцев. И.К. Багратион-Мухранский, как до него М.И. Кутузов при Бородино или царь Леонид в последнем бою при Фермопилах, организовывал Ингурский бой «не как борьбу за победу, а как... требуемое политикой кровопускание» $[15$, с. 92], и оценивать это сражение следует именно в свете его политических последствий.

Результаты. Политические последствия Ингурского сражения. Время доказало правоту командующего Гурийским отрядом. Партизанская война в Мингрелии не разгорелась немедленно после отступления русских войск от Ингура, но сражение создало для нее политическую почву. Вскоре после боя мингрельская знать выступила в поддержку борьбы с турками и засвидетельствовала свою верность княгине Е.А. Дадиани [6, c. 32-33], а ведь именно отсутствие поддержки со стороны местной аристократии являлось, по мнению участника кампании, одной из основных причин турецкой неудачи [21, 


\section{ВСЕОБЩАЯ ИСТОРИЯ}

p. 126]. Многочисленные послания, в которых Омер-паша убеждал правительницу края вернуться в Зугдиди и продолжать управлять Мингрелией [6, с. 34-36, 39-40], свидетельствуют о неустойчивости его положения: если бы турецкая оккупация зиждилась на прочном политическом и социальном фундаменте, не было бы настоятельной необходимости подкреплять ее легитимностью вдовствующей княгини. К концу ноября продвижение Омер-паши к р. Цхенис-Цхали, к которой русские войска отступили после Ингурского боя, остановилось в условиях осенней распутицы, и вскоре турецкая армия начала отход к своим береговым базам. С этого момента выступления против армии Омерпаши, носившие до того спорадический характер, развернулись в полную силу: партизаны обстреливали колонны на марше, отрезали фуражировочные партии от главных сил, а мирное население «помогало им всеми средствами» $[21$, p. 182]. Особенно важно отметить, что на Кавказском ТВД местное население редко участвовало в военных действиях по собственной инициативе: еще М.И. Богданович указывал на крайнюю маловероятность народной войны без прямой поддержки регулярных войск [5, с. 113]. Таким образом, Мингрелия осенью 1855 г. являет собой примечательное исключение, и на роль фактора, обеспечившего столь нетипичное развитие событий, лучше всего подходит именно Ингурское сражение. И.К. Багратион-Мухранский не разгромил противника в бою, но создал политическую обстановку, в которой даже малейшего признака слабости, такого как отказ от атаки русских позиций на Цхенис-Цхали, было достаточно, чтобы земля загорелась у Омерпаши под ногами.

Немаловажно также отметить, что батумское оперативное направление, на котором разворачивался поход Омер-паши, было неудобно для энергичных действий регулярных войск из-за пересеченной местности и сложных погодных условий. Осенняя распутица, вынудившая к остановке армию Омерпаши, уже может служить достаточным подтверждением этого тезиса, но немало свидетельств в его пользу можно найти и в других эпизодах войны. Так, после сражения на p. Чолок 3 (15) июня 1854 г. преследованием наголову разбитого Батумского корпуса турок занималась лишь конная милиция на протяжении 2 часов, что отражено в рапорте генерал-лейтенанта И.М. Андроникова генерал-лейтенанту В.О. Бебутову [1, с. 801]. Такое решение было принято именно из-за сложной местности, не позволявшей энергично развивать успех. При этом неудобства батумского направления для регулярных войск оборачивались преимуществами для партизан, не обремененных артиллерией, менее зависимых от снабжения, прекрасно знакомых с местностью и пользовавшихся поддержкой местного населения. Современник событий имел основания заявить, что «нет края более удобного для партизанской войны» $[7$, с. 20], чем Мингрелия. Английский автор, прошедший вместе с турками всю кампанию, также признавал, что действия партизан оказались для войск Омер-паши существенно опасней их единственного столкновения с регулярной русской армией [21, p. 130] (пусть и не отдавая себе отчета в том, что без второго не было бы и первого). Создав благоприятную для партизанской войны политическую обстановку, И.К. Багратион-Мухранский смог не только вернуть Мингрелию под русский контроль, но и сделать это наиболее эффективным для условий оперативного направления способом.

Таким образом, подлинное значение Ингурского сражения в кампанию 1855 г. на Кавказском ТВД раскрывается только при его рассмотрении с политической точки зрения. Потерпев безоговорочное тактическое поражение в посредственно проведенном бою, И.К. Багратион-Мухранский тем не менее сумел решить более важную политическую задачу. Готовность России отстаивать Мингрелию, продемонстрированная на берегах Ингура, подтвердила состоятельность русской власти в глазах местного населения и подготовила благодатную почву для партизанской войны, сыгравшей важную роль в неудаче Омер-паши. Учитывая это, сражение на р. Ингур 25 октября (6 ноября) 1855 г. следует оценивать не как плачевное поражение, а как разумное подчинение тактики политике, оправдавшее себя в ближайшей перспективе. 


\section{СПИСОК ЛИТЕРАТУРЫ}

1. Акты Кавказской археографической комиссии. В 12 т. Т. 10 / под ред. А. П. Берже. - Тифлис : Тип. Канцелярии Главноначальствующего гражд. частью на Кавказе, 1885. - 938 с.

2. Акты Кавказской археографической комиссии. В 12 т. Т. 11 / под ред. Д. А. Кобякова. Тифлис : Тип. Канцелярии Главноначальствующего гражданской частью на Кавказе, 1888. - 1020 с.

3. Бескровный, Л. Г. Русское военное искусство ХІХ века / Л. Г. Бескровный. - М. : Наука, 1974. $361 \mathrm{c}$.

4. Бестужев, И. В. Оборона Закавказья в Крымской войне 1853-1856 годов / И. В. Бестужев // Вопросы истории. - 1954. - Т. 29, № 12. - С. 53-66.

5. Богданович, М. И. Крымская война, 18531856 гг. / М. И. Богданович. - М. : Эксмо, 2014. $672 \mathrm{c}$.

6. Бороздин, К. Омер-паша в Мингрелии: из воспоминаний о Восточной войне 1853-56 годов / К. Бороздин. - СПб. : Тип. Департамента уделов, $1873 .-58 \mathrm{c}$.

7. Бурчуладзе, Е. Е. Крушение англо-турецких захватнических планов в Грузии в 1855-1856 годах / Е. Е. Бурчуладзе // Вопросы истории. - 1952. T. 27, № 4. - C. 10-24.

8. Дегоев, В. В. Кавказский вопрос в международных отношениях 30-60-х гг. ХІХ в. / В. В. Дегоев ; под ред. Н. С. Киняпиной. - Владикавказ : Изд-во СОГУ, 1992.-328 с.

9. Ибрагимбейли, Х.-М. Кавказ в Крымской войне 1853-1856 гг. и международные отношения / Х.-М. Ибрагимбейли. - М. : Наука, 1971. - 404 с.

10. Киняпина, Н. С. Кавказ и Средняя Азия во внешней политике России (вторая половина XVIII 80-е годы XIX в.) / Н. С. Киняпина, М. М, Блиев, В. В. Дегоев. -М. : Изд-во МГУ, 1984. - 312 с.

11. Клаузевиц, К. О войне / К. Клаузевиц ; пер. А. Рачинского. - М. : Госвоениздат, 1934. - 649 с.

12. Победа при Башкадикляре (19 ноября 1853). Частное письмо Э.В. Бриммера // Русский архив. - 1904. - Т. 42, № 9. - С. 125-137.

13. Потто, В. А. Блокада и штурм Карса (по неизданным запискам П.Я. Бакланова и рассказам прочих участников в событии) / В. А. Потто // Русская старина. - 1870. - Т. 2, № 12.- С. 567-610.

14. Тарле, Е. В. Крымская война. В 2 т. Т. 2 / Е. В. Тарле. - М. : АСТ, 2005. - 720 с.

15. Свечин, А. А. Стратегия / А. А. Свечин.М. : Прибой, 1927. - 263 с.

16. Свечин, А. А. Эволюция военного искусства с древнейших времен до наших дней. В 2 т. Т. 1 / А. А. Свечин. - М. ; Л. : Военгиз, 1927. - 385 с.

17. Скрицкий, Н. В. Крымская война. 18531856 годы / Н. В. Скрицкий. - М. : Вече, 2006. - 416 с.
18. Allen, W. E. D. Caucasian Battlefields /W. E. D. Allen, P. Muratoff. - Cambridge : Cambridge UP, 1953. - XXII, 614 p.

19. Badem, C. The Ottoman Crimean War / C. Badem. - Leiden : BRILL, 2010. -432 p.

20. Buzzard, T. With the Turkish Army in the Crimea and Asia Minor: A Personal Narrative / T. Buzzard. - L. : John Murray, 1915. - VIII, 310 p.

21. Oliphant, L. The Trans-Caucasian Campaign of the Turkish Army under Omer-Pasha / L. Oliphant. - L. : William Blackwood and Sons, 1856. - XXVII, $234 \mathrm{p}$.

22. The Siege of Kars, 1855. Defence and Capitulation, Reported by General Williams. - L. : Stationery Office : [s. n.], 2000. - 260 p.

\section{REFERENCES}

1. Berge A.P., ed. Akty Kavkazskoy arkheograficheskoy komissii. V12 t. T. 10 [Acts of Caucasian Archaeographical Commission. In 12 vols. Vol. 10]. Tiflis, Tip. Kantselyarii Glavnonachalstvuyushchego grazhd. chastyu na Kavkaze, 1885. 938 p.

2. Kobyakov D.A., ed. Akty Kavkazskoy arkheograficheskoy komissii. V 12 t. T. 11 [Acts of Caucasian Archaeographical Commission. In 12 vols. Vol. 11]. Tiflis, Tip. Kantselyarii Glavnonachalstvuyushchego grazhd. chastyu na Kavkaze, 1888. 1020 p.

3. Beskrovnyy L.G. Russkoe voennoe iskusstvo $X I X$ veka [Russian Military Art of the $19^{\text {th }}$ Century]. Moscow, Nauka Publ., 1974. 361 p.

4. Bestuzhev I.V. Oborona Zakavkazya v Krymskoy voyne 1853-1856 godov [Defense of Transcaucasia in the Crimean War of 1853-1856]. Voprosy istorii [Questions of History], 1954, vol. 29, no. 12 , pp. 53-66.

5. Bogdanovich M.I. Krymskaya voyna, 1853-1856 gg. [The Crimean War of 1853-1856]. Moscow, Eksmo Publ., 2014. 672 p.

6. Borozdin K. Omer-pasha v Mingrelii: iz vospominaniy o Vostochnoy voyne 1853-56 godov [Omer-pasha in Mingrelia: From the Recollections of the Oriental War of 1853-1856]. Saint Petersburg, Tip. Departamenta udelov, 1873. $58 \mathrm{p}$.

7. Burchuladze E.E. Krushenie angloturetskikh zakhvatnicheskikh planov v Gruzii v 1855-1856 godakh [Failure of Anglo-Turkish Expansionist Plans in Georgia in 1855-1856]. Voprosy istorii [Questions of History], 1952, vol. 27 , no. 4 , pp. 10-24.

8. Degoev V.V. Kavkazskiy vopros v mezhdunarodnykh otnosheniyakh 30-60-kh gg. $X I X v$. [Caucasian Question in the International 
Relations in the 1830s - 1860s]. Vladikavkaz, Izd-vo SOGU, 1990. 328 p.

9. Ibragimbeili H.-M. Kavkaz v Krymskoy voyne 1853-1856 gg. i mezhdunarodnye otnosheniya [Caucasus in the Crimean War of 1853-1856 and International Relations]. Moscow, Nauka Publ., 1971. $404 \mathrm{p}$.

10. Kinyapina N.S., Bliev M.M., Degoev V.V. Kavkaz i Srednyaya Aziya vo vneshney politike Rossii (vtoraya polovina XVIII-80-e gody XIX v.) [Caucasus and Central Asia in the Foreign Politics of Russia (Second Half of the 18th Century - the 1880s)]. Moscow, Izd-vo MGU, 1984. 312 p.

11. Clausewitz C. O voyne [On War]. Transl. by A. Rachinkiy. Moscow, Gosvoenizdat Publ., 1934. 649 p.

12. Pobeda pri Bashkadiklyare (19 noyabrya 1853). Chastnoe pismo E. V. Brimmera [Victory at Başgedikler on November 19, 1853: Private Letter by E.V. Brimmer]. Russkiy arkhiv [Russian Archive], 1904, vol. 42, no. 9, pp. 125-137.

13. Potto V.A. Blokada i shturm Karsa (po neizdannym zapiskam P.YA. Baklanova i rasskazam prochikh uchastnikov v sobytii) [The Blockade and Assault of Kars (Based on I.P. Baklanov's Unpublished Notes and the Recollections of Other Participants in the Event]. Russkaya starina [Russian Antiquity], 1870, vol. 2, no. 12, pp. 567-610.
14. Tarle E.V. Krymskaya voyna. V2 t. T. 2 [The Crimean War. In 2 vols. Vol. 2]. Moscow, AST Publ., 2005. 720 p.

15. Svechin A.A. Strategiya [Strategy]. Moscow, Priboy Publ., 1927. 263 p.

16. Svechin A.A. Evolyutsiya voennogo iskusstva s drevneyshikh vremen do nashikh dney. V 2 t. T. 1 [The Evolution of Military Art from the Most Ancient Times to Our Days. In 2 vols. Vol. 1]. Moscow, Leningrad, Voengiz Publ., 1927. 385 p.

17. Skritskiy N.V. Krymskaya voyna. 18531856 gody [The Crimean War. 1853-1856]. Moscow, Veche Publ., 2006. 416 p.

18. Allen W. E. D., Muratoff P. Caucasian Battlefields. Cambridge, Cambridge UP, 1953. XXII, $614 \mathrm{p}$.

19. Badem C. The Ottoman Crimean War. Leiden, BRILL, 2010. 432 p.

20. Buzzard T. With the Turkish Army in the Crimea and Asia Minor: A Personal Narrative. London, John Murray, 1915. VIII, 310 p.

21. Oliphant L. The Trans-Caucasian Campaign of the Turkish Army under Omer-Pasha. London, William Blackwood and Sons, 1856. XXVII, 234 p.

22. The Siege of Kars, 1855. Defence and Capitulation, Reported by General Williams. London, Stationery Office, 2000. 260 p.

\section{Information about the Author}

Dmitriy Yu. Plotnikov, Postgraduate Student, Trainee Researcher, Institute of History of the Siberian Branch, RAS, Akademika Nikolaeva St., 8, 630090 Novosibirsk, Russian Federation, d.plotnikov@alumni.nsu.ru, https://orcid.org/0000-0001-9284-7898

\section{Информация об авторе}

Дмитрий Юрьевич Плотников, аспирант, стажер-исследователь, Институт истории Сибирского отделения РАН, ул. Академика Николаева, 8, 630090 г. Новосибирск, Российская Федерация, d.plotnikov@alumni.nsu.ru, https://orcid.org/0000-0001-9284-7898 